NASA Technical Memorandum 107139

AIAA-96-0936

\title{
Low Gravity Guidance System for Airborne Microgravity Research
}

W.J. Rieke, E.F. Emery, and E.O. Boyer

Lewis Research Center

Cleveland, Ohio

C. Hegedus and D.P. O'Donoghue NYMA, Inc.

Brook Park, Ohio

Prepared for the 34th Aerospace Sciences Meeting and Exhibit sponsored by the American Institute of Aeronautics and Astronautics Reno, Nevada, January 15-18, 1996

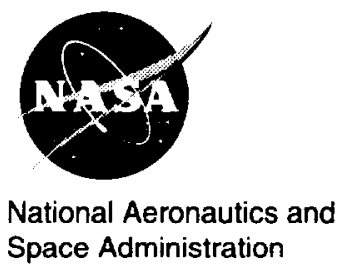

National Aeronautics
Space Administration 
Trade names or manufacturers' names are used in this report for identification only. This usage does not constitute an official endorsement, either expressed or implied, by the National Aeronautics and Space Administration. 


\title{
LOW GRAVITY GUIDANCE SYSTEM FOR AIRBORNE MICROGRAVITY RESEARCH
}

\author{
W.J. Rieke, E.F. Emery and E.O. Boyer \\ National Aeronautics and Space Administration \\ Lewis Research Center \\ Cleveland, Ohio 44135 \\ C. Hegedus and D.P. O' Donoghue \\ NYMA, Inc. \\ Brook Park, Ohio 44142
}

\begin{abstract}
Microgravity research techniques have been established to achieve a greater understanding of the role of gravity in the fundamentals of a variety of physical phenomena and material processing. One technique in use at the NASA. Lewis Research Center involves flying Keplarian trajectories with a modified Lear Jet and DC-9 aircraft to achieve a highly accurate Microgravity environment by neutralizing accelerations in all three axis of the aircraft. The Low Gravity Guidance System (LGGS) assists the pilot and copilot in flying the trajectories by displaying the aircraft acceleration data in a graphical display format.

The Low Gravity Guidance System is a microprocessor based system that acquires and displays the aircraft acceleration information. This information is presented using an electroluminescent display mounted over the pilots instrument panel. The pilot can select the Microgravity range that is required for a given research event.

This paper describes the characteristics, design, calibration and testing of the Low Gravity Guidance System Phase III, significant lessons learned from earlier systems and the developmental work on future systems.
\end{abstract}

\section{INTRODUCTION}

In the last few years the demand for a suborbital Microgravity environment has grown substantially. Drop tubes or towers are capable of generating high quality low gravity but generally for very short durations. Suborbital sounding rockets can also produce a very high quality low gravity environment. However, this method involves considerable cost associated with miniaturization and preparation.

The large scale use of aircraft to provide low gravity was begun in the late 1950's at the request of a joint Air Force Systems Command/National Aeronautics and Space Administration Survey Panel that proposed the increased use of aircraft to conduct low gravity research. These flights were initiated at Wright Patterson AFB and used the C-131 and C-135 aircraft.' Shortly thereafter, the NASA Lewis Research Center began using an AJ-2 and B-57 to support the increasing demands for a low gravity environment required by the expanding Space program.

Aircraft produced Microgravity, unlike drop tubes or sounding rockets, has the advantage of generating multiple data points (Trajectories) without disassembly or repositioning of the test rig. The researcher may also accompany the experiment to observe or make adjustments between data points. Aircraft are also able to generate fractional acceleration levels such as Lunar gravity

Recently there has been an increased demand for the use of aircraft as a cost effective method to generate low gravity. The NASA Lewis Research Center has responded to that need with available aircraft and, more importantly, increasingly sophisticated guidance systems to enhance the overall quality of the low gravity environment.

This effort toward accurate and user friendly guidance systems began in 1984 when the Lewis Research Center modified a Lear 25 aircraft for use as a Microgravity facility. It has been a continuing process of refinement and redesign since that time. The current system in use on the NASA DC-9 aircraft is software driven and can be optimized for aircraft characteristics and pilot ergonometrics. 


\section{EARLY GUIDANCE SYSTEMS}

Early guidance systems attempted accurate measurement and control primarily in the aircraft body-fixed vertical axis or " $Z$ " axis. These early systems incorporated analog needle gages that measured a voltage range form remotely placed accelerometers. This was a major improvement over the mechanical " $G$ " meters used in most tactical military aircraft at the time. However, this necessitated the use of two gages in the " $Z$ " axis, one for high and one for low resolution. In addition to resolution being somewhat limited by gage size, this arrangement required the pilot to change his point of reference when maneuvering from high to low "G".

\section{SECOND GENERATION SYSTEMS}

The second generation guidance system used three LED bar-graph displays to present the output of three bodyfixed accelerometers mounted near the aircraft center of gravity. ${ }^{2}$ This allowed each display to be more easily aligned with the axis it represented to enhance pilot interpretation and control.

This system also facilitated the movement from low to high resolution required in the " $\mathrm{Z}$ " axis during the maneuver from high to low "G". Initially this system incorporated a logarithmic scale around the target level of acceleration. The target acceleration is normally centered on 0 " $G$ " but may be varied to almost any fractional acceleration level needed in this and subsequent displays.

Further refinement resulted in abandoning the pure logarithmic scale for a break from low to high resolution in order to enlarge the number of LED's within the target (acceptable) level of acceleration. For this system it was determined through flight test that the " $Z$ " axis resolution should be approximately $0.002 \mathrm{G}$ in the high resolution scale and the range of the high resolution (Or expanded area) on the display be sufficient to account for expected slight variations around the target acceleration. ${ }^{3}$

The major disadvantage of the display was limited data resolution due to the discrete nature of the individual LED's in the bar graph and the resultant breakout nature of the guidance being presented within the target acceleration area.

In this system the LEDs are activated by voltage comparator circuitry and inherently contain hysterisis for an LED state change. The hysterisis proved to be a problem in providing trend information close to the setpoint and determining the corresponding control movements. The problem is further compounded by the log nature of the data near the setpoint indicator. Relatively large variations in acceleration data would be required before the next LED in sequence would change state due to logarithmic step quantities designed into the system. Immediate trend and data states were difficult to determine and produced a situation in slightly turbulent air that made maintaining the setpoint conditions very difficult. Display modifications required extensive lead time to develop and fabricate new circuit boards, LED mounts and display cover templates every time a variation in the data display was required.

The system, however, was a significant improvement over the analog needle method previously used and allowed significant time increase between $\pm 0.010 \mathrm{G}$ and $\pm 0.020 \mathrm{G}$ of the setpoint

In addition the system was sufficiently sophisticated that active control of the " $\mathrm{X}$ " (Thrust) axis was possible without major compromise of the " $Z$ " axis that normally occurs because of pitch/power coupling and resulting higher pilot workloads. However, the throttle technique used by the pilot not flying the "Z" axis (Normally the co-pilot) was critical due to the pitch coupling effects. Previous to this it was believed that precise " $Z$ " axis control was possible only by abandoning active control of the " $\mathrm{X}$ " axis and flying the trajectory with prepositioned throttles. ${ }^{1,3}$

\section{THE PRESENT GUIDANCE SYSTEM - PHASE III}

The system and display currently in use was developed for the DC-9 and initially flight tested on a Model 25 Lear Jet at the Lewis Research Center.

With availability of a suitable electroluminiscent display $(640 \times 350$ pixels), improved hardware and sophisticated software, a guidance system was developed that allowed more accurate control of the " $Z$ " axis acceleration and therefore further enhanced the quality of the low gravity environment.

\section{SYSTEM OVERVIEW}

The Low Gravity Guidance System (LGGS) used on the DC-9 consists of a triaxial accelerometer block, linear phase filters, a STD computer and an electoluminescent display (figure 1). The accelerometers are mounted on the cabin 
floor near the aircraft center of gravity. The accelerometers are body-fixed and measure the aircraft accelerations in the longitudinal, lateral and vertical axis. The output is in an analog format connected to linear phase filters. The filters are located in an equipment rack in what was the forward galley area in the aircraft. The filters provide the signal conditioning and cut-off frequency of $5 \mathrm{~Hz}$ required to band limit the accelerometer information before the conversion to digital format by the STD 16 bit AN board. The STD computer digitizes the output and displays it in a graphical format on the electroluminescent display that can be attached to the aircraft instrument panel. A "Z" axis selector switch is located on the flight deck to allow the flight crew selection of the desired target " $\mathrm{Z}$ " axis acceleration level.

\section{THE DISPLAY}

The electorluminescent display is of significant importance for the following reasons:

It allows dynamic scaling and eliminates the problems with the discrete nature associated with individual LED's when used in a bar graph. Within the target acceleration area, this is a significant improvement.

The graphic presentation is capable of taking advantage of the full length and width of the display.

Combined analog and digital presentations of "G" levels can included on the same display. This is of particular importance in the higher " $G$ " levels during the pull up maneuver.

The scale at the target acceleration can be highlighted, enlarged, or repositioned for ease of use.

Operational warnings such as over "G" conditions in the "Z" axis can be presented dramatically or superimposed over the guidance data.

Display brilliance is such that direct sunlight does not washout the presentation.

\section{SYSTEM DEVELOPMENT}

The initial requirement for a computer display oriented system came about in an effort to provide optimized trend information and data resolution to fly the Microgravity trajectory. The earlier LED display provided only 20 discrete steps on the physical display. Five LEDs at the outer region of either side of setpoint were a linear representation of $G$ level and the inner five LEDs either side of the setpoint were a logarithmic representation of $G$ level.

The initial solution to the trend problem was to increase the number of distinct data points available on a display. A computer display was identified as a suitable solution due to its pixel density. Emerging flat panel technology provided the solution for installation of a computer compatible display in a small cockpit environment.

The LeRC Lear Jet model 25 was used as the initial platform to develop the software procedures and display scale parameters. Initial bargraph positioning and scaling were addressed during the first flights. A result of the flight testing demonstrated that a logarithmic display tended to confuse the pilot by providing too great of a pixel change per analog to digital converter count change and further use of the log type bargraph was curtailed. The scaling on the physical display (pixel per inch) and the corresponding numeric scaling of $G$ data (pixel per count per $G$ ) upon the display were identified as the critical system gains. Values for these gains were determined empirically for each acceleration axis. The data scan rate was determined by the evaluation of spectral data from the accelerometers. The display data refresh rate was set to provide reduced flicker along with sufficient damping of changing bargraph data for easy interpretation.

\section{HARDWARE DESCRIPTION}

LGGS design is composed with an industrial STD Bus computer system, triaxial accelerometer set, digital filter mainframe, video extender and electroluminescent display. The system design satisfies NASA safety design criteria.

The accelerometers are Sundstrand's linear servoaccelerometers. The accelerometers are mounted orthogonal in a mounting block attached to a precision triaxial mounting base. The mounting base provides fine tuning of the accelerometers alignment with the respect to the aircraft.

The linear phase filters are modified bessel 6 pole, 6 zero time delay quad filters/amplifiers. The amplifiers have differential inputs and provide pre-filter gain, post-filter gain and sensor zero suppression capability. The quad 
filters/amplifiers are a board mounted plug in type that are housed inside a nineteen inch rack mountable mainframe. The filters/amplifiers are user programmable either through the front panel or through the IEEE GPIB port on the back. The filter system is mounted in an equipment rack located in what was the forward galley area.

The STD system has been chosen for its durability and ability to withstand the typical research flight environment while satisfying the three basic requirements for the installation of electronics that are to be installed on an aircraft: 1) Power 2) Volume 3) Weight. The STD Bus computer system involves the following: 1) computer bus chassis 2) cpu card 3) hard drive 4) video card 5) analog to digital card and 6) discrete $V O$ card. ${ }^{6}$ The chassis is built for an industrial environment and is powered by the existing aircraft power distribution. The cpu and analog to digital cards were chosen for their data computational and through-put capabilities.

The LGGS display is a flat panel electroluminescent type based on IBM PC video standards and is mounted on the pilot's side of the cockpit with its aspect rotated 90 degrees to provide maximum pixels for the full scale $Z$ axis data (Fig.3 ). The location was chosen to optimize pilot readability as affected by view angle and nominal ambient sun light in the cockpit during the Microgravity mission. Selector buttons are located in the cockpit near the throttle quadrant to allow the flight crew to select a $\mathrm{G}$ level setpoint and an alternate triaxial accelerometer block that may be mounted near the front of the cabin.

\section{SOFTWARE DESCRIPTION}

The LGGS code was compiled using a C++ compiler.' The code is modular for ease of adding functions and other modifications which may be required by the flight research crew as a result of operational assessment using the system.

The code calculates and projects data in bar graph form on the display with the fine scale axes oriented with the aircraft control movement making control changes intuitive with aircraft control movements. The display portion also contains the appropriate auto scaling rules to provide the proper pixel to $\mathrm{G}$ ratios. These ratios are important in helping the pilot interpret the $\mathrm{G}$ data. Other modules within the code provide event trigger, alarm functions, discrete VO sense and data digitization.

\section{SYSTEM EVALUATION IN THE DC-9}

Flight evaluation of the prototype system was accomplished by pilots with considerable experience flying all versions of the previous system. The major concern was the design of the presentation itself and the update rate of the " $Z$ " axis.

It must be pointed out that control of the " $\mathrm{X}$ " axis is significantly easier than the " $\mathrm{Z}$ " axis and requires training only in the proper throttle technique so as not to degrade " $Z$ " axis control due to previously mentioned pitch/power coupling. The "Y" axis is normally controlled by the yaw damper but may be controlled by the pilot if required.

Since an electroluminescent display is used, many versions of the guidance presentation were possible. The finalized version is shown in figure 1 and evolved from subjective evaluation of many possible presentations. With the system in use for over one year, it has proven to be exceptionally user friendly and allows pilots to enter the setpoint limits expeditiously and to control the " $\mathrm{Z}$ " axis within the setpoint for longer durations.

\section{THE FOURTH GENERATION}

The forth generation Low Gravity Guidance System, currently in development, will be a true pilot guidance system. The goal of this development program is to increase the consistency of high quality low gravity trajectories per flight by providing the pilot with computed flight control input commands through the display.

A full parameter identification flight test program will be conducted to characterize the aircrafi's stability and control coefficients during all phases of the Microgravity maneuver. These parameters will be used in the development of the guidance control law. Input states will include airspeed, pitch, roll and yaw attitudes/rates, three-axis accelerations, and elevator, aileron, rudder and throttle positions. Output commands will be pitch and roll control position, and rudder and throttle position. It is expected that some degree of 'lead compensation' and 'control mode shaping' will be incorporated into the control law to accommodate for the long control mode time constants and low aircraft frequency response of the DC-9.

The 'raw-data' presentation of three-axis accelerations, featured on the current LGGS, will be replaced by a 'flight director' presentation. The flight director will guide the pilot through the optimum low-gravity trajectory by directing the appropriate control inputs. The final configuration of this display will be determined through piloted-evaluations during 
flight test of the system. It is expected that the guidance display commands will be band limited to somewhere below $2.0 \mathrm{~Hz}$ to prevent the pilot inadvertently driving the control inputs out-of-phase with the aircraft response.

\section{SUMMARY}

The role of aircraft in the production of a Microgravity environment for science and engineering studies is becoming more commonplace. Many aircraft can generate reduced gravity for varying amounts of time and with wide variations in quality. However, the time and quality of the Microgravity environment can be improved significantly with a pilot guidance system that is optimized for aircraft characteristics and pilot ergonometrics.

The end result of this advanced design and presentation is consistent high quality, repeatable trajectories and therefore a higher degree of accuracy in sub-orbital Microgravity research.

\section{REFERENCES}

1. Useller, J. W., Enders, J.H., Haise, F.W. "Use of Aircraft for Zero Gravity Environment," NASA TN D-3380, 1966

2. Millis, M.G. "Acceleration Display System for Aircraft Zero Gravity Research," NASA TM-87358, 1987

3. Boyer, E.O., Rieke, W. J., Grodsinsky, C.M. "Microgravity Research on the NASA Lewis Learjet Test Facility"

AIAA-93-0573, 1993

4. Crabs, C.C. "The Lewis Center Aircraft Zero Gravity Test Facilities," Paper prepared for NASA Zero Gravity Conference, 1963

5. Hammer, L.R. "Aeronautical Systems Division Studies in Weightlessness 1959-1960" Report WADD TR 60-715, Wright Patterson AFB, OH, 1961

6. Ziatech Industrial Computer System Manual (For BIOS Version 4.0), Ziatech Corporation, San Luis Obispo, CA

7. Borland C++ Compiler (Version 4.01), Borland Intemational, Inc., Scotts Valley, CA

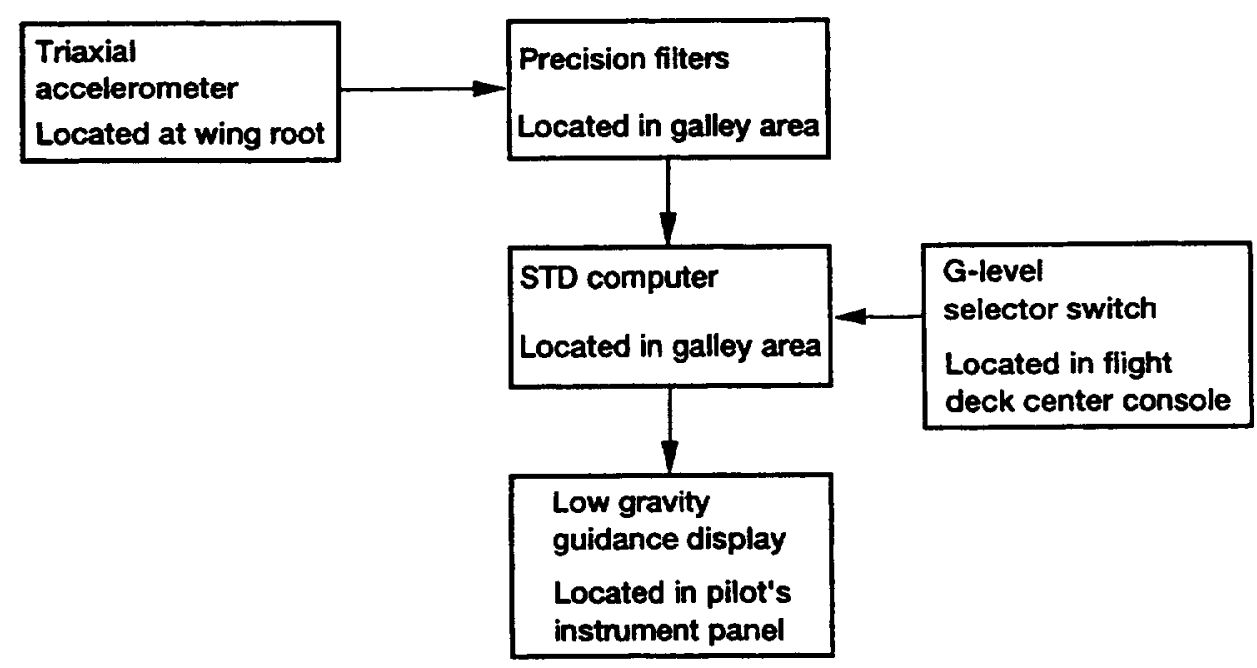

Figure 1.-Low gravity guidance system diagram. 


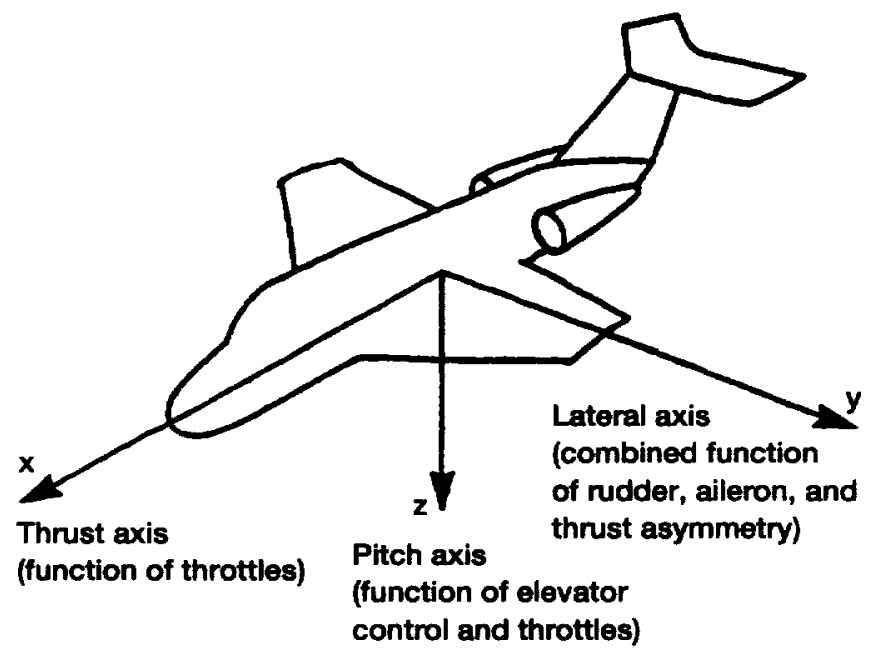

Figure 2.-Axes orientation.

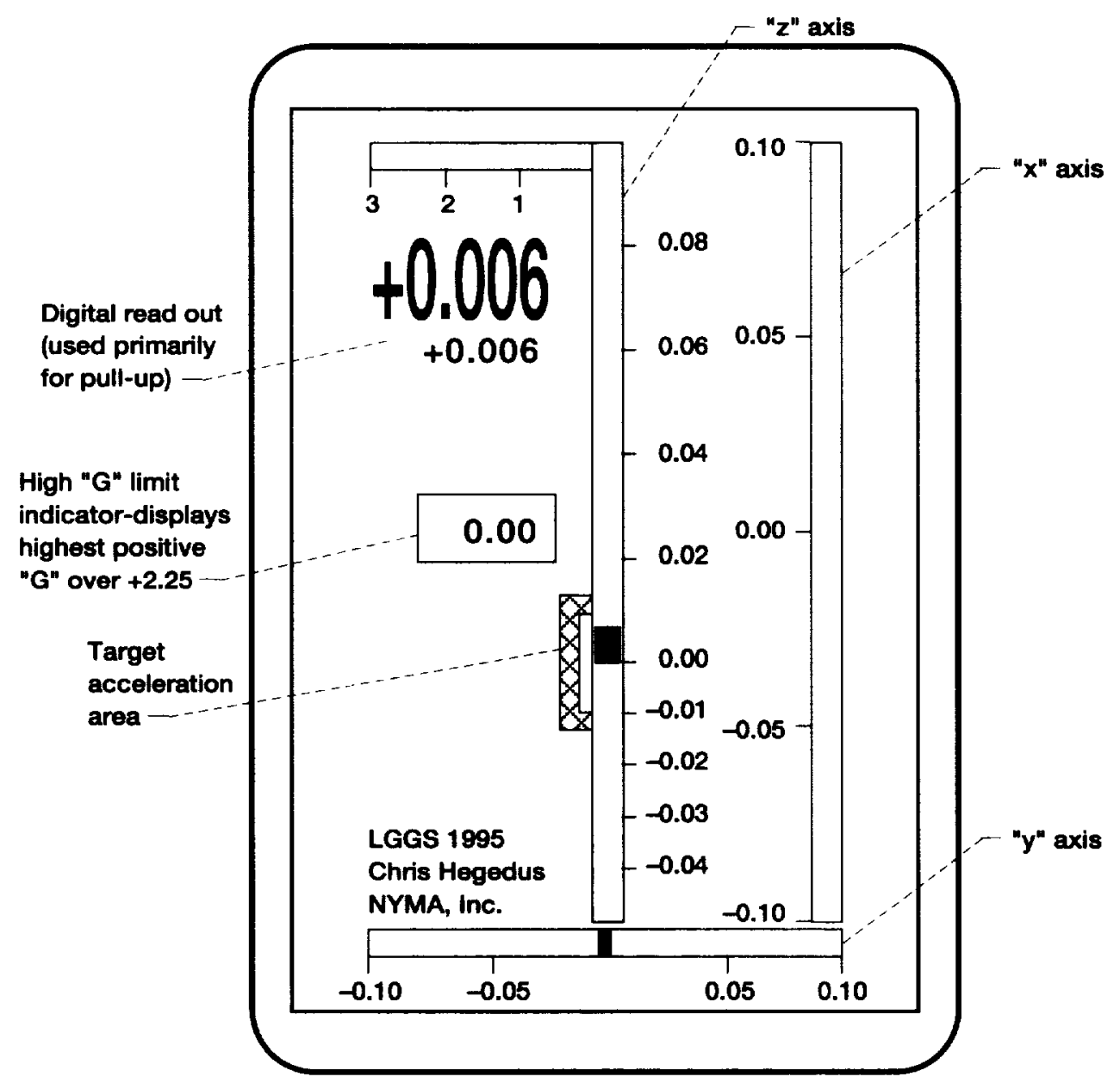

Figure 3.-Low gravity guidance system display. 


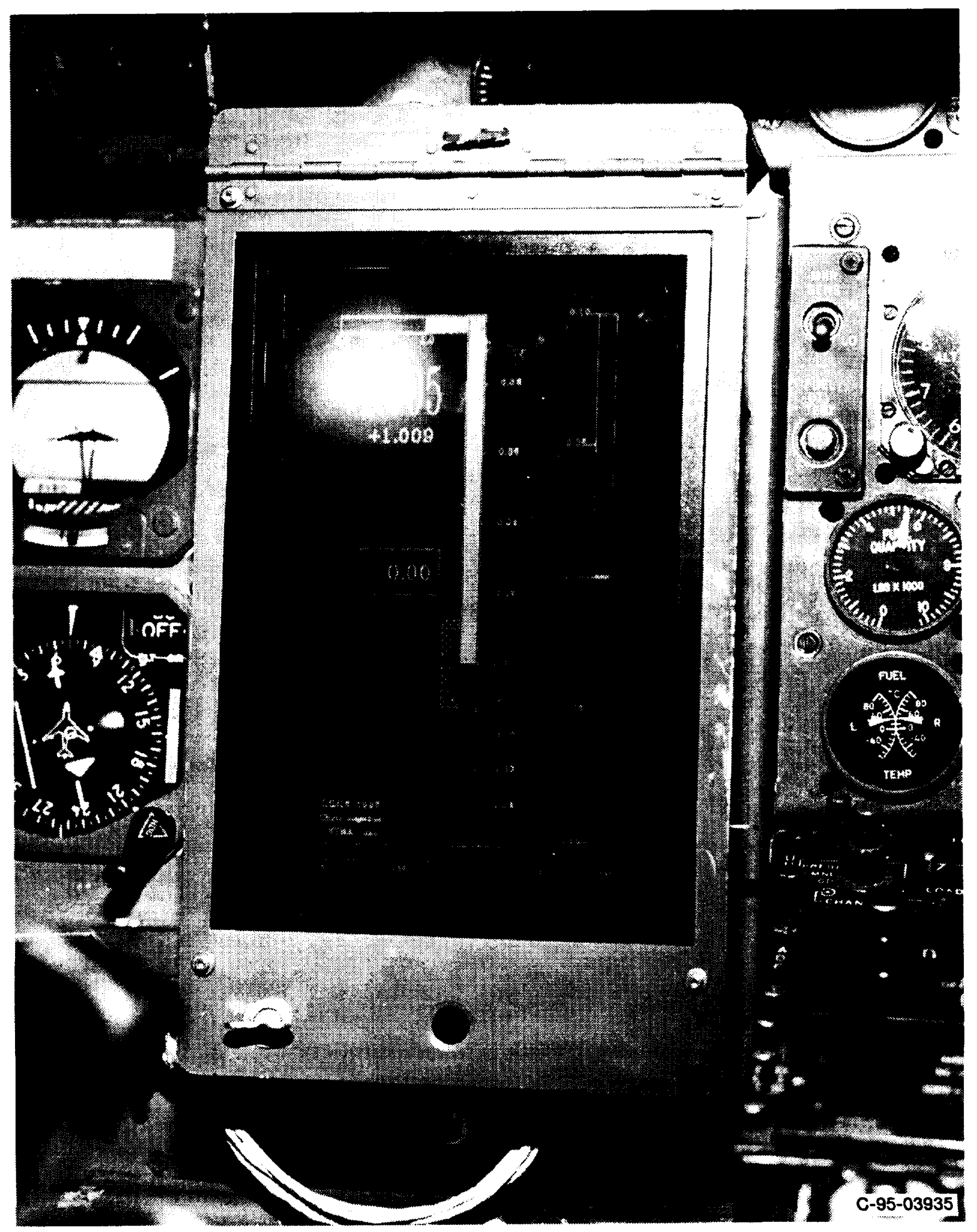

Figure 4.-Close up of low gravity guidance system display. 


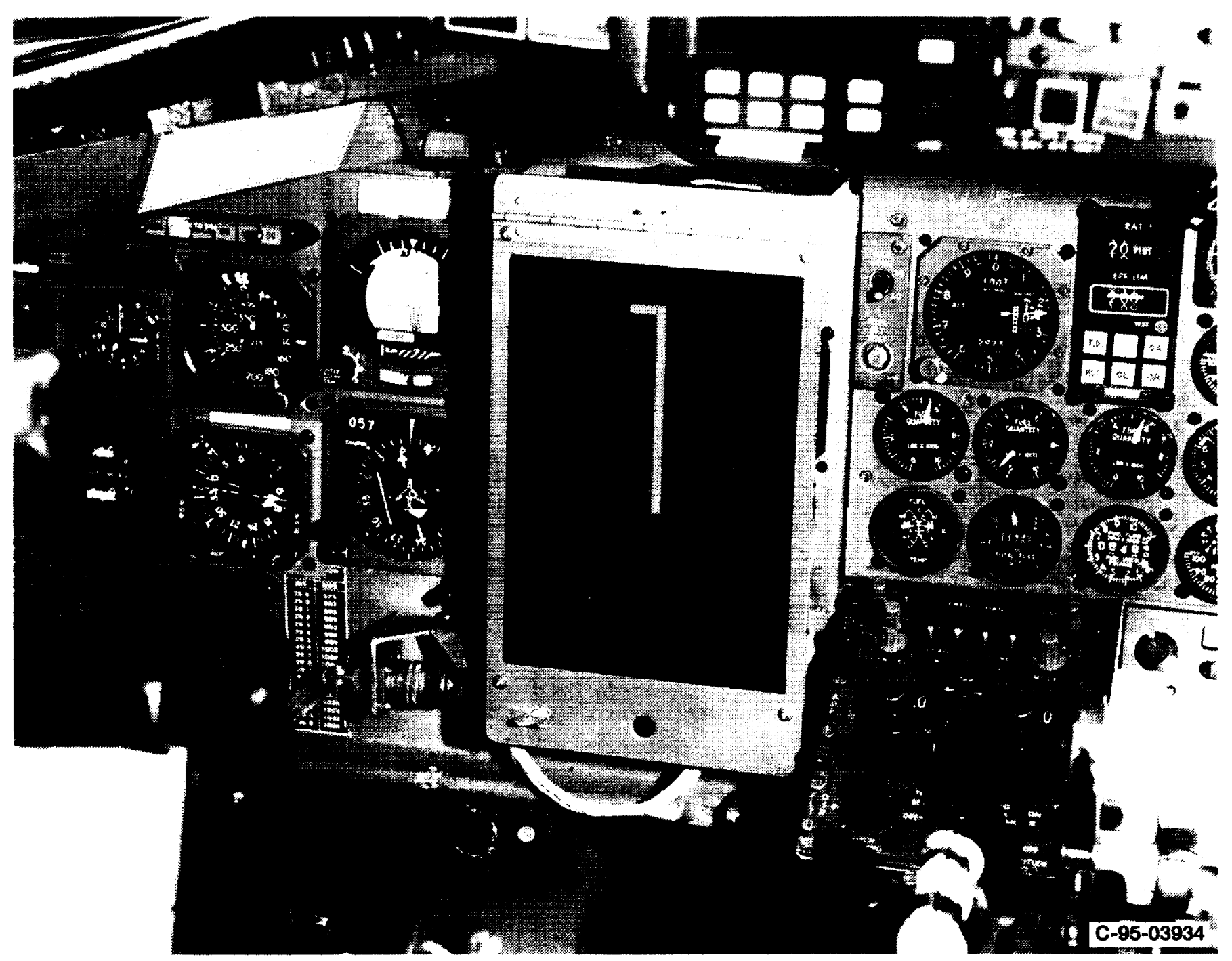

Figure 5.-Low gravity guidance system as installed in DC-9 cockpit. 



\begin{tabular}{|c|c|c|c|c|}
\hline \multicolumn{3}{|c|}{ REPORT DOCUMENTATION PAGE } & & $\begin{array}{l}\text { Form Approved } \\
\text { OMB No. 0704-0188 }\end{array}$ \\
\hline \multicolumn{5}{|c|}{ 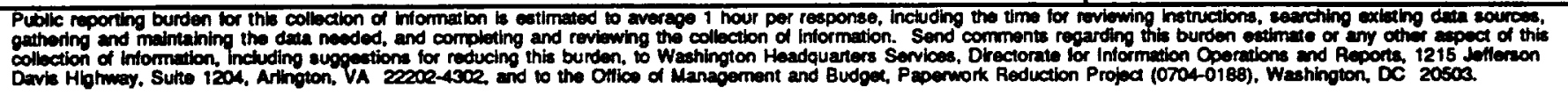 } \\
\hline 1. AGENCY USE ONLY (Leave blank) & \begin{tabular}{l|l} 
I REPOAT DATE \\
November 1996
\end{tabular} & \multicolumn{3}{|c|}{$\begin{array}{l}\text { 3. REPORT TYPE AND DATES COVERED } \\
\text { Technical Memorandum }\end{array}$} \\
\hline \multicolumn{3}{|c|}{$\begin{array}{l}\text { 4. TIRE AND SUBTIRLE } \\
\text { Low Gravity Guidance System for Airborne Microgravity Research }\end{array}$} & \multicolumn{2}{|c|}{ 5. FUNDING NUMBERS } \\
\hline \multicolumn{3}{|c|}{$\begin{array}{l}\text { 6. AUTHOR(S) } \\
\text { WJ. Rieke, E.F. Emery, E.O. Boyer, C. Hegedus, and D.P. O'Donoghue }\end{array}$} & \multicolumn{2}{|c|}{ WU-963-80-0E } \\
\hline \multicolumn{3}{|c|}{$\begin{array}{l}\text { 7. PERFORMNG OAGANAZATION NAME(S) AND ADDRESS(ES) } \\
\text { National Aeronautics and Space Administration } \\
\text { Lewis Research Center } \\
\text { Cleveland, Ohio } 44135-3191\end{array}$} & \multicolumn{2}{|c|}{$\begin{array}{l}\text { 8. PERFORIMNG ORGANIZATION } \\
\text { REPORT NUMBER }\end{array}$} \\
\hline \multicolumn{3}{|c|}{ 9. SPONSOFANGMONITORING AGENCY NAME(S) AND ADDRESS(ES) } & \multicolumn{2}{|c|}{$\begin{array}{l}\text { 10. SPONSOPAMGMONITOAING } \\
\text { AGENCY REPORT NUMBER } \\
\text { NASA TM-107139 } \\
\text { ALAA-96-0936 }\end{array}$} \\
\hline \multicolumn{5}{|c|}{$\begin{array}{l}\text { 11. SUPPLEMENTARY NOTES } \\
\text { Prepared for the 34th Aerospace Sciences Meeting and Exhibit sponsored by the American Institute of Aeronautics and Astronautics, } \\
\text { Reno, Nevada, January 15-18, 1996. WJ. Rieke, E.F. Emery, and E.O. Boyer, NASA Lewis Research Center, C. Hegedus and D.P. } \\
\text { ODonoghue, NYMA, Inc., 2001 Aerospace Parkway, Brook Park, Ohio } 44142 \text { (work funded by NASA Contract NAS3-27186). } \\
\text { Responsible persom. WJ. Rieke, organization code 2860, (216) 433-2036. }\end{array}$} \\
\hline \multicolumn{4}{|c|}{$\begin{array}{l}\text { 12a. DISTRIBUTRONAVALABILTY STATEMENT } \\
\text { Unclassified - Unlimited } \\
\text { Subject Category } 06 \\
\text { This publication is available from the NASA Center for AeroSpace Information, (301) 621-0390. }\end{array}$} & 12b. DISTRABUTION CODE \\
\hline \multicolumn{5}{|c|}{$\begin{array}{l}\text { Microgravity research techniques have been established to achieve a greater understanding of the role of gravity in the } \\
\text { fundamentals of a variety of physical phenomena and material processing. One technique in use at the NASA Lewis } \\
\text { Research Center involves flying Keplarian trajectories with a modified Lear Jet and DC-9 aircraft to achieve a highly } \\
\text { accurate Microgravity environment by neutralizing accelerations in all three axis of the aircraft. The Low Gravity Guid- } \\
\text { ance System (LGGS) assists the pilot and copilot in flying the trajectories by displaying the aircraft acceleration data in a } \\
\text { graphical display format. The Low Gravity Guidance System is a microprocessor based system that acquires and displays } \\
\text { the aircraft acceleration information. This information is presented using an electroluminescent display mounted over the } \\
\text { pilots instrument panel. The pilot can select the Microgravity range that is required for a given research event. This paper } \\
\text { describes the characteristics, design, calibration and testing of the Low Gravity Guidance System Phase III, significant } \\
\text { lessons from earlier systems and the developmental work on future systems. }\end{array}$} \\
\hline \multirow{2}{*}{\multicolumn{2}{|c|}{$\begin{array}{l}\text { 14. SUBJECT TERIMS } \\
\text { Microgravity guidance }\end{array}$}} & & & $\begin{array}{l}\text { 15. NUMBER OF PAGES } \\
10\end{array}$ \\
\hline & & & & $\begin{array}{l}\text { 16. PRICE CODE } \\
\text { AO2 }\end{array}$ \\
\hline $\begin{array}{l}\text { 17. SECURTY CLASSIFICATION } \\
\text { OF REPORT } \\
\text { Unclassified }\end{array}$ & $\begin{array}{l}\text { 18. SECURTY CLASSIFICATION } \\
\text { OF THIS PAGE } \\
\text { Unclassified }\end{array}$ & $\begin{array}{l}\text { 19. SEC } \\
\text { OF }\end{array}$ & ATION & 20. LIMITATION OF ABSTRACT \\
\hline
\end{tabular}

